\title{
Anatomisation and Dissection
}

Once opportunities for clemency or escape-a pardon, commuted sentence, or other reprieve-had passed, capital conviction meant one thing: execution. However, death at the end of a hangman's rope, while often taken as a clear conclusion in studies of crime and punishment, was not the end of the judicial process, nor the end of the criminal's narrative journey or their capacity to play a powerful and meaningful role in the social, scientific and cultural life of the nation. ${ }^{1}$ As we have seen, power inhered in the criminal body far beyond the spectacle and moment of execution, whether in terms of persistent vitality, such as instances of asynchronous legal and medical death, ${ }^{2}$ or as an object giving rise to fear, fascination, disgust and desire. ${ }^{3}$ The criminal corpse was the locus of new spectacles of state power, post-mortem punishments shaped by retributive justice, and modern scientific experimentation. Further, the living prisoner and the criminal corpse did not exist in a neat dichotomy, one becoming the other thanks to a short drop and sudden stop. As medical men worked with the bodies they received via the Murder Act, it became clear that the lines between life and death-and consequently, between live prisoner and criminal corpse-were far less clear than might be expected. This chapter picks up the story of the criminal corpses produced through convictions and executions under the Murder Act, specifically of those sentenced to the post-mortem punishment of anatomisation and dissection, and follows the fates of these bodies as

(C) The Author(s) 2018

S. Tarlow and E. Battell Lowman, Harnessing the Power of the Criminal Corpse, Palgrave Historical Studies in the Criminal Corpse and its Afterlife, https://doi.org/10.1007/978-3-319-77908-9_5 
they moved through the nexus of medical knowledge, dismemberment, public spectacle, death and decay.

The criminal corpse is our focus here, but we must also ask: who were the people working with these bodies, and why did they choose to do so? The answer begins by noting the close tie between the Murder Act and the changing status of medical dissection. By stipulating that the body of a murderer 'shall be dissected and anatomized by the said Surgeons, or such person as they shall appoint for that purpose', ${ }^{4}$ the Murder Act created an official role for medical professionals in the British criminal justice system. Until 1745, the Company of Barber-Surgeons essentially held a monopoly on accrediting surgeons, but this monopoly was hardly a barrier to calling oneself a surgeon. Many men with a variety of accreditations, or in fact no accreditation at all, commonly claimed to be surgeons. This began to change in 1745 when the Company of Surgeons was formed in London following a long-anticipated split from the Company of Barber-Surgeons. In 1752, 'surgeon' became a standardised qualification, and the Company of Surgeons gained the largely exclusive power of accreditation. There is a further divide in the application of the term between those who sought and gained this accreditation for the purpose of general practice-called 'apothecary-surgeons'-and those who conducted surgery specifically within the penal system-'penal surgeons'. This is an important distinction. An apothecary-surgeon required accreditation, and many apothecary-surgeons also served as penal surgeons, but not all penal surgeons were so accredited and they did not all work as apothecary-surgeons. This was especially true outside of London, where surgeons were scarcer, and the presence of the Company of Surgeons somewhat more distant. These penal surgeons were often men who held some other medical experience or credential, and were locally respected for their knowledge and skills.

Surgeons were not the sole agents of the state involved in conducting anatomisation and dissection. Rather, a broader medical community was involved in fulfilling this role under the Murder Act, including physicians, students and the paid staff of the Company (such as porters and beadles). Given the imprecision of the term 'surgeon' in this period, and the numerous other actors involved in carrying out this post-mortem punishment, ${ }^{5}$ it is perhaps most accurate to speak of 'medical men': a largely (if not exclusively) homosocial group of adherents to the burgeoning medical-scientific complex, ranging from experts in human anatomy, to clerks and craftspeople who can be understood as stakeholders 
with practical investment in the judicial process. It was these medical men-of all stripes-who were critical to carrying out the sentence of anatomisation and dissection and staging the public and professional spectacles that followed death on the gallows.

Historical literature has paid scant attention to post-execution rites, though the spectacle and process of execution has been of considerable interest to historians of Britain's long eighteenth century. ${ }^{6}$ However, more by omission than deliberate neglect, this created the mistaken impression that penal surgeons handled only 'dead bodies from the gallows and that capital penalties from a medical standpoint were straightforward once a criminal stopped jerking on the hangman's rope' ${ }^{7}$ What happened after the sentence of legal death was accomplished on the gallows is much more complex, blurring the lines between life and death, and giving rise to a whole suite of post-execution rites, processes and spectacles. This chapter takes up the journey of the criminal corpse from the foot of the scaffold and into the spaces of the first of the post-mortem punishments mandated by the Murder Act: anatomisation and dissection.

\section{Duty, Death, AND Discretion}

Under the Murder Act, surgeons (and within Middlesex and London, the Company of Surgeons) were charged with the duty of anatomising and dissecting the corpses of executed murderers sentenced to suffer these 'marks of infamy'. ${ }^{8}$ Anatomisation in this context refers to an established process of opening the corpse and checking vital organs-the heart and lungs up to 1812, and the heart, lungs, and brain thereafterin order to establish death with certainty. ${ }^{9}$ Dissection in this context is best understood as the further infliction of post-mortem harm on the body for medical training and research purposes. Anatomisation including displaying its results to the execution crowd and dissection required medical men to take a leading role in both the practice and the public display of this post-mortem punishment.

Though medical men had long been peripherally related to the criminal justice system-tending sick prisoners who could afford treatment while in gaol, and obtaining the pre-Murder Act bodies allotted them from the gallows for dissection in the service of medical training-the Murder Act for the first time made medical professionals formal actors in the British criminal justice system. ${ }^{10}$ As surgeons were made responsible for executing a key stage in the punishment of those deemed 
society's worst offenders, the connection between medicine and criminal justice became fixed in the public imagination. Over the course of the eighteenth century, extensive coverage in the popular press, street ballads, and other entertainments built and hardened the association of executions with medical training and professionalisation. ${ }^{11}$ The presence of the medical men at executions and public dissections, performing both ceremonial and practical public functions, allowed average folk to confirm these associations with their own eyes. This helped to generate powerful and enduring impressions of medical men as both agents of the state, and of death, at times to their dismay. ${ }^{12}$

It is easy to draw a simple association between medical men and execution and dissection under the Murder Act, but the degree to which surgeons and others could exercise agency within and even against the juridical regime created by the Act is not obvious. The Act is remarkably clear in stipulating some matters related to sentencing and punishing convicted murderers, including the conditions of confinement of the condemned before execution, the timing of sentencing and execution, and the choice between two mandated post-mortem punishments. The Act is far less clear when it comes to key elements of the sentence of dissection and anatomisation. It did not stipulate where and when the procedures should take place, who should be present, or how long the punishment should last, instructing only that the body be taken to the appointed surgeon, and that in no case whatsoever the body of any murderer shall be suffered to be buried; unless after such body shall have been dissected and anatomized'. ${ }^{13}$ This created both the space and necessity for those involved in executing the sentence of post-mortem punishment to develop protocols of their own through practice and example. The medical men had to determine in carrying out this post-mortem punishment: how publicly visible their work would be, what types of anatomical techniques they would employ, how much of a body would be left afterward, what parts might be kept and preserved, and how, when, and where the remains would be disposed of. ${ }^{14}$ Sometimes, as we shall see, this included life-and-death decisions.

\section{'I'm Not Dead Yet!' Medical Men and the Uncertainty of Death}

The punishment for capital crimes in eighteenth and nineteenth century Britain was to be hanged by the neck until dead. But death on the gallows was no easy thing. Those of us more accustomed to depictions of 
hanging in television and films than historical and actual hangings likely have a distorted idea of how this form of execution looks, kills, or smells.

Under the procedures in place during the time of the Murder Act, death on the gallows was never totally certain-legally or otherwise. ${ }^{15}$ We are likely more familiar with the clinical precision of the ideal 'long drop' in which the upper cervical vertebrae are quickly fractured or dislocated when the body's acceleration as it falls is stopped short by the noose, the sudden jerk and resulting trauma to the neck causing immediate unconsciousness and rapid death. ${ }^{16}$ But this innovation, and the speedy death it promised, was not introduced until well after the period of the Murder Act. ${ }^{17}$ Instead, the 'short drop' was the method used to hang those sentenced to die in Britain in the eighteenth and early nineteenth centuries. ${ }^{18}$

In Britain, the condemned were taken to the gallows with their arms tied; a cap was placed over their face and the noose placed around their neck. Then, the cart, ladder, or trapdoor on which they stood was removed, leaving them to dangle by their neck at the end of the taught rope. Usually the individual began to die of strangulation, their skin stretching under the weight of their body, their neck dislocating. ${ }^{19}$ Should the neck not break, the restriction of blood flow created incredible pressure inside the head, resulting in protruding eyes, the face turning vivid purple, then black, and the brain turning into a 'bloody mush'. ${ }^{20}$ The pressure and trauma caused the body to evacuate. Faeces and urine were joined by sex-specific discharges-in men, the release of seminal fluid and in women, spontaneous menstruation as the uterus prolapsed. ${ }^{21}$ Death by the short drop was excruciatingly painful and unavoidably messy.

The effectiveness of this method of execution depended a great deal on the hangman's individual skill but also on other factors, some difficult to overcome. Ideally, bodies were left to hang for an hour to ensure death. In newspaper reports on hangings during this period, this was described as leaving the body to hang 'for the usual time'. However, in summer months, the heat made it unpleasant to leave a body hanging for the full hour. Conversely, cold temperatures in winter could send a body into hypothermic shock, slowing life signs so that it was difficult to determine if death had occurred, necessitating longer waits. Further, perspiration from fear or heat could make the noose slip and slide and affixing the noose in the most effective way could be equally difficult if prisoners struggled. Finally, the physical attributes of the condemned 
could make hanging more difficult or prevent death on the gallows. The 'bull necked' posed a particular problem as strong muscles could protect the arteries in the neck from being constricted by the rope, allowing (some) blood flow to continue. ${ }^{22}$ Though implicit, it was also clear that 'the appointed executioner was duty-bound to ensure that the condemned died on the rope'. ${ }^{23}$ However, the capital code did not allow the use of bladed weapons to finish off the condemned so the hangman, or family and friends of the dying, could only resort to handling the body more roughly — in particular, tugging on the legs — to ensure or speed up death by strangulation or broken neck if this was thought necessary. ${ }^{24}$

With so many factors influencing the effectiveness of short drop hanging, it is no surprise that not everyone brought down from the gallows was dead. In cases sometimes referred to as the 'half-hanged', individuals revived after hanging. ${ }^{25}$ Brenda Cook has identified 13 instances of individuals surviving execution by hanging and reviving afterward in Britain between 1587 and 1785, and of these 2 were immediately re-hanged, and 5 died of the injuries sustained from their mandated punishment. ${ }^{26}$ Though remarkable and very well reported in the press, revival after execution was atypical. Much more common was finding that a body brought down from the gallows, though incapable of revival, was evidently not yet completely dead.

The issue of death, or rather the uncertainty of determining death, was well discussed in medical circles in the two centuries before the advent of the Murder Act. The combination of a less than one hundred percent effective method of execution with complicating factors such as weather or particularly robust physiques, or variations in the amount of time a body was left to hang, meant that some of those sentenced to death for murder actually died elsewhere in the presence of, or at the hands of, the surgeons. Accounts of anatomists beginning dissections on bodies thought dead that subsequently-and sometimes, spectacularlyrevived were widely circulated, including being retold in J.B. Winslow's instructions on responsibilities, timings, and techniques for medical men in his important 1746 volume, The Uncertainty of the Signs of Death, and the Dangers of Precipitate Interments and Dissections, Demonstrated. ${ }^{27}$ In one well-known case from the sixteenth century, Winslow mentions that the anatomist began cutting into the 'corpse' provided to him, only to discover the dead person was in fact still alive-but not for long, as the anatomist's initial cuts completed the job. Consequently, the anatomist was chased out of town by enraged members of the public shouting 
'Murderer!' The pursuit of medical knowledge was not without risk, a fact of which the medical men of the eighteenth and nineteenth centuries were only too aware, and a point to which we return later in this chapter.

In the years immediately preceding the Murder Act, Winslow noted the difficulty of determining death in cases of hanging as 'we are often deceived with respect to the Signs of Death' and many of the ways death might be identified-including the colour of the face, flexibility of the limbs, temperature of the body, and the 'abolition of the external senses' - are 'very dubious and fallacious Signs of a Certain Death'. ${ }^{28}$ Winslow concluded that the only truly infallible way to determine death was to wait for decomposition to begin. This was contrary to the needs of anatomical work, but the moral and ethical orthodoxy of the day held that it was better to wait than to accidentally cause death with the surgeon's blade. The celebrated anatomist Jean Riolan (the Younger, 1577-1657) specifically addressed the issue of uncertainty of death and state-sanctioned dissection:

[S]peaking of the Bodies of hanged Persons, by public Authority destined to Dissection... That so long as the Body is warm, and the Person but lately executed, we are not to dissect him; since, if there is still any Prospect of recalling him to Life, we are equally bound by the Principles of Humanity and Charity to do all we can for that Purpose, in order to procure him, if possible, a favourable Opportunity of Repentance. ${ }^{29}$

Riolan prioritised the preservation of life and the avoidance of foreclosing on any opportunity for a person to 'die properly' - that is, to be given the opportunity for repentance and thus salvation-over and above the potential anatomical benefits of beginning a dissection quickly in order to make use of the body while it was as fresh, and therefore as useful, as possible. In this way, Riolan effectively advocated yielding to the importance of the time of the dead, instead of anatomical time. Winslow noted that Terilli, the celebrated early seventeenth-century physician of Venice, was even stronger in his call to delay dissection until true death could be confirmed, and the imperative for the medical men to yield to the time of the dead, because:

[The Body] is sometimes so depriv'd of every vital Function, and the Principle of Life reduc'd so low, that it cannot be distinguished from Death, the Laws both of natural Compassion and reveal'd Religion oblige 
us to wait a sufficient Time for Life's manifesting itself by the usual Signs, provided it should not be as yet totally extinguished; and if we should act a contrary Part, we may possibly become Murderers, by confining to the gloomy Regions of the Dead, those who are actually alive. ${ }^{30}$

This concern about the anatomist-as-murderer in cases where bodies reached medical men before life had completely left the body led Winslow to argue that the best practice was to leave the supposedly dead individual supine with a pillow under the head and covered by a blanket, and to wait two or three days. By this time, either a return to life or an incontrovertible death would have taken place, and one imagines that after three days death could be easily confirmed by smell alone. ${ }^{31}$

In the case of those executed under the Murder Act, the 'time of the dead' was not held sacrosanct in the way Winslow and Riolan might have preferred. Elizabeth Hurren writes about the case of John Holloway, sentenced to death and dissection in 1831 for the 'horrible murder, almost unparalleled in atrocity' ${ }^{32}$ of his wife, Celia Holloway. Being strong of neck, Holloway was considered a 'dangerous' body because even after an hour on the scaffold, his neck wasn't broken, meaning there was a risk that he might revive. Hurren writes that 'The body now had to be made safe by the surgeon' by severing the carotid artery (in the neck) to speed up the dying process. ${ }^{33}$ Coming towards the end of the life of the Murder Act, we now know that this instance of a surgeon assuring or causing the medical death of the condemned was no isolated incident. Hurren has found a startling number of cases in which criminal corpses received by the medical men were not in a state of absolute death. The records of William Clift, who worked at Surgeon's Hall in London show that between 1812 and 1830, of 35 well-documented cases, there were 10 in which the condemned was not yet medically dead, that is 'the heart was still beating after the body was received'. ${ }^{34}$ Did Clift and others in his place follow the strong calls by Riolan, Terilli, and Winslow to wait for absolute death before proceeding? In a word: no.

It was not just common knowledge but also a generally unchallenged practice that medical men might end the lives of condemned criminals, despite the prohibition on completing the work of the noose with a blade. As a newspaper correspondent wrote in 1769: 'the business of Surgeon's Hall is not to revive and frustrate but to complete the Execution of the Sentence in Cases of Murder'. ${ }^{35}$ In the case that the body of a hanged murderer delivered to the medical men under 
the Murder Act showed any sign of life, the first duty of the surgeon was to 'use the lancet to commit a merciful act' ${ }^{36}$ - that is, to supplement the hangman's rope with the penal surgeon's lancet to complete the transformation from condemned to corpse. In large part this was a result of the challenges in the use of short-drop hanging as the exclusive method of execution during this period, but it was also because of the great difficulty in distinguishing between the two physiological types of death identified in the eighteenth and nineteenth centuries: 'the name of death', in which a body was unresponsive to stimuli, and 'absolute death', signalled by a complete physical shutdown. ${ }^{37}$ We will return to the issue of determining death, and the work the medical men conducted with bodies in the state between the name of death and absolute death in the final section of this chapter; what we want to underscore here is the role of the medical men in relation to the criminal justice system. The Murder Act refers to the surgeon as being responsible for anatomising and dissecting the bodies of those sentenced under the Act. Unofficially, but indisputably, the surgeon was also responsible for causing or hastening death. In some cases, they were co-executioners.

\section{Between Science, Spectacle and the State}

Under the terms of the Act, those murderers not sentenced to hang in chains were sentenced to anatomisation and dissection. The letter of the law appears straightforward here, particularly as the two terms were (and in some cases, still are) used interchangeably. The bottom line was that the surgeons would cut the murderer's corpse, and that burial was not permitted until this had taken place. In practice, however, carrying out this sentence was anything but clear-cut once the medical men were in possession of a body. For the surgeons, their actions were dictated not only by the law, but also by the execution crowd. Both of these external pressures were further affected by the personal and professional capabilities and priorities of the medical men themselves. Execution crowds in eighteenth- and nineteenth-century Britain were regularly thousands-strong. Drawn by the spectacle of punishment, by the frisson of excitement, the carnivalesque crowds were at once attracted to and repulsed by the visceral display, responding to life, death, authority, each other and the criminals themselves. ${ }^{38}$ Thomas Laqueur has argued that the crowd 'was the central actor in English executions', 39 while Peter Linebaugh has established that the crowd was able to exercise a 
significant amount of power through strong, collective reactions to anatomists at work. ${ }^{40}$ However, studies to date have usually left the crowd (along with the corpse) at the gallows. By intent or omission this neglects the significant power of the execution crowd in relation to punishment that did not end at the hanging tree.

One of our key findings in tracing the journey of the criminal corpse is that the post-execution crowd was a key actor in determining the location and extent of public post-mortem punishment of those convicted under the Murder Act. ${ }^{41}$ Post-execution, the crowd also expected to see the post-mortem punishment and to participate. The reasons for the crowd's interest in witnessing and participating in the punishment of the corpse are similar to the reasons for attending the execution. However, we argue that four key elements fuelled the crowd's interest in seeing the body of a murderer opened and exposed: the urge to see that justice had been done and the evildoer was well and truly dead (with no risk of resurrection); 'natural curiosity' about the dangerous dead, as murderers and other criminals were often at the centre of news, gossip, and local folk tales; curiosity about the shaved, nude, fleshy body which was otherwise rarely seen in public, including a particular interest in the sexual organs which, in the case of hanged men, may have been in a state resembling excitement; and the prestige of proximity and witnessing a well-known event that would become part of history, granting the participant the right to declare 'I was there!' The post-execution crowd clamoured for access, and to deny them was dangerous and difficult, if not impossible.

Though not written into the Murder Act or specifically mandated by the criminal justice system, making the post-mortem punishment of anatomisation and dissection a public event did serve State interests. As discussed in the previous chapter, the Act was intended to deter potential murders by inspiring horror at the prospect of the dismembering and decay of their body and the denial of respectable burial and its associated rites. The shame and humiliation of public dissection supported this end, as evidenced by tales of prisoners described as stoic during the pronouncement of execution, but who lost their nerve at the prospect or sentencing of post-mortem dissection. ${ }^{42}$ Further, in the eighteenth and early nineteenth centuries, justice had to be done locally, which is to say that justice had to be meted out in front of local audiences for justice to be seen to be done. Prior to the advent of mass media, news tended to circulate regionally, and it was difficult to separate fact from 
fiction as stories travelled across distances and in many versions, and were interpreted in a range of class, cultural and personal contexts. ${ }^{43}$ Seeing was-quite literally-believing when it came to the delivery of justice. While it is true and not inconsequential that the state benefitted from public post-mortem punishment in the way that it increased the terror and infamy of the punishment for murder, it was the crowd that drove the public imperative. For example, the courtyard of the Shire Hall in Derby was altered in 1752 to permit the crowd a better view of executions and the transportation of the corpse from the gallows into the room used for dissection. Railings and gates were added (through which the crowd entered to walk around the displayed corpse) in the hope that by better permitting controlled visual and physical access that the crowd would be satisfied and less likely to riot. ${ }^{44}$ Clearly, the crowd did not lose interest in the criminal or the punishment spectacle once it could be called a corpse. Rather, public interest remained strong and as such, spectators had to be accommodated in two senses: they had to be allowed physical access to view the bodies opened by the surgeons, and they had to be allowed conceptual access in that the post-mortem punishment had to meet their expectations of such a spectacle so that they would be satisfied, and disperse.

To allow the crowd physical access to see the anatomised criminal corpse, the body had to be brought to a place where it could be displayed and people could see it, usually by moving past the corpse in long queues. For this reason, a variety of public and semi-public spaces close to the site of execution were used as dissection and anatomisation venues. ${ }^{45}$ Hurren has identified four broad types of spaces used for this purpose. ${ }^{46}$ In the north of England to the west of the Pennines, it was common to use small public dispensaries; in the Midlands, the local Shire Hall was a preferred site; in London, before criminal corpses were taken to central locations for private anatomical work, public anatomisationparticularly in the cases of very violent murderers-was sometimes conducted at the site of the crime to increase the symbolic impact of the punishment ${ }^{47}$; finally, in the West Country, post-mortem punishment of murderers was carried out in prison rooms, the domestic premises of the surgeon, or in a medical dispensary. ${ }^{48}$ Indeed, Hurren's central finding is that "post-mortem "harm" was always located in public spaces in which it would gain greater acceptance by a wide cross-section of the community'. ${ }^{49}$ The local and accessible nature of post-mortem punishment under the Murder Act was necessary to effectively convey the importance 
of punishing murderers in particularly degrading or torturous ways, a component of expanding social control as discussed in the previous chapter. Making criminal anatomisations local and highly visible during the same period that the actual numbers of capital convictions for murder were declining significantly increased the impact and the scope of influence of the punishment for murder. During this period the State increasingly worked to limit interaction between the crowd and medical men at the site of execution. The reverse was true in the places and spaces where the post-mortem punishment was conducted, where the public was encouraged to crowd around, cheer and jeer, and otherwise turn the site into a macabre carnival. ${ }^{50}$ State actors knew quite well that, for post-mortem punishments to have an impact on the public, they had to be conducted in a place accessible to large numbers.

In many respects, the requirement for the crowd to have physical access to the post-mortem spectacle dictated the parameters for the spaces in which the medical men could execute their duty under the Act-large enough and central enough to house the excited onlookers, while also providing a clear, central space for the medical men to stage or work on the corpse. ${ }^{51}$ However, the conceptual access required by the crowd also influenced the anatomical procedures the medical men chose to perform during their work. The anatomical procedures that supported the teaching and research needs of the medical men were impossible in the context of demonstration for the post-execution crowd. A lack of sanitation and contamination of the body were common issues, as was the lack of light, quiet, appropriate storage facilities, and specialised tools that might be difficult or impractical to transport. Further, the uses to which the medical men wanted to put these bodies did not necessarily align with the expectations of the crowd. They wanted to see a body that still looked like a body and this was impossible should the medical men proceed in accordance with their teaching and research interests, often meaning detailed examination of particular organs and dissection 'to the extremities'. This type of dissection resulted in only about a third of the body remaining intact, as organs were removed and further dissected, flesh and cartilage removed from bone, circulatory systems carefully disassembled, reassembled and mapped, and various other disintegrations. ${ }^{52}$

Surgical anatomists already had a poor public reputation, stemming from the grisliness of their long-standing use of corpses granted them from the gallows, and their reputation for illegally buying bodies stolen 
from graves. Upsetting the crowd's expectations could mean intense reprisals, including being chased from town by an angry mob, and more usually vandalism or damage to the places used to display or conduct anatomisation and dissection. ${ }^{53}$ The medical men, therefore, had to develop practices that allowed the negotiation between their duty in the criminal justice system, the expectations of the crowd, and the exigencies of their own interests in these corpses.

The medical men engineered a balance by disambiguating their actions into two distinct processes - anatomisation and dissection-and by working specifically to satisfy the expectations of the crowd so that they could conclude the public and criminal justice aspect of their work as quickly as possible and repair to their anatomy rooms with the corpse while it was still in a useful state, before significant decay had begun. While the full process of anatomisation and dissection might differ, as did the meaning and use of these terms between people and regions, penal surgeons frequently used them interchangeably to refer to the cutting of a body to reveal or allow the study of internal structures and the workings of the body, and to confirm death. This took advantage of ambiguity in the wording of the Murder Act, which referred clearly to anatomisation and dissection, but made no distinction between the two, allowing medical men to develop their own clarifications to suit their multiple needs. ${ }^{54}$

Given the primacy placed on ensuring a criminal had become a corpse before truly committing to dissection for both punishment and educational purposes, the confirmation of death through anatomisation became the first duty. This procedure involved checking to ensure the body was now lifeless and confirming this for the crowd by putting it on display for the public to see. ${ }^{55}$ In order to achieve the desired effect, including displaying a body that was still recognisable and showed harm had been done to the corpse, the surgeons typically made cuts deep enough to check that the heart and lungs (and later, brain) had lost function, but not necessarily involving the mass opening or removal of large pieces of flesh, such as the breast plate and rib cage or whole limbs. Anatomisation usually involved making two intersecting cuts-one from about neck to groin, and a perpendicular cut across the chest or abdomen-to permit manual and some visual access to the main organs. As one example, the anatomisation of William Corder, executed in 1828 for the murder of Maria Martin, was described in detail in newspaper reports ${ }^{56}$ : 
Mr. Creed, the county surgeon, assisted by Mr. Smith and Mr. Dalton, made a longitudinal incision along the chest as far as the abdominal parts, and deprived it of the skin so as to exhibit the muscles of the chest. ${ }^{57}$

These cuts allowed the surgeons to slice into the main muscles, peel back the skin, and expose to view the organs (possibly removing some). The body, stripped of all or most clothing - in the case of men doubly exposed through shaving ${ }^{58}$ — and presented with long cuts exposing muscles and organs for display fulfilled the public's idea of what medical dissection should look like while simultaneously presenting an identifiable criminal who had clearly received the mandated punishment, all while preserving as much of the body as possible for later anatomical use (Fig. 5.1).

Dissection allowed the surgeons much greater latitude to pursue their own priorities with respect to the criminal corpse. First, this usually involved moving the body to a venue better suited to medical work and

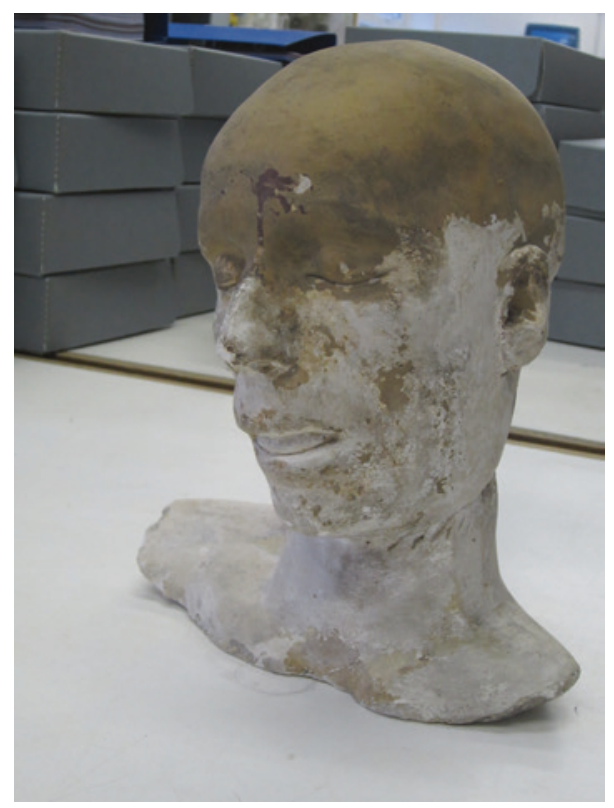

Fig. 5.1 Cast of a hanged criminal's head, owned by Winchester Museums (Photo: S. Tarlow) 
then conducting as many as seven different anatomical procedures, until 'the murderer was despoiled as a human being'. ${ }^{59}$ Dissection, then, was the element of the punishment mandated in the Murder Act that allowed medical men to make use of criminal corpses in ways much more closely aligned with their own priorities and needs, and without the same imperative to play to an audience and maintain public perceptions of what an executed and punished murderer should look like. To illustrate this, we return to the post-mortem punishment of William Corder: once anatomisation and the public access and viewing involved was complete, the corpse was moved from the Shire Hall to the County Hospital. Here, the same surgeons who had performed the anatomisation dissected before an audience of 'medical gentlemen':

Mr. Creed, jun. assisted by Mr. C. Smith, and Mr. Dalton, commenced the operations; they first minutely dissected the muscles of the chest, and having elevated the sternum, and examined the lungs, they took out the intestines, all of which appeared in a most healthy state. From the formation of the chest, it did not appear that Corder would have been a likely subject for pulmonary affection. The medical students heard demonstrations upon the respective parts that were anatomized; there were some Italian artists there, who took two or three excellent casts of his head (Fig. 5.2), as also a celebrated craniologist, who informed us that the organs of 'destructiveness and secretiveness' were strongly developed, as also that of 'Philoprogenitiveness' (or love of children); but there was a total want of every other. His forehead was flat and not disproportioned; though small, not being more than five feet six inches high, yet he was well formed, and showed a considerable share of muscle. ${ }^{60}$

Dissection, then, was a much more involved surgical procedure that, like anatomisation, could serve the needs of a demanding audience.

However, the decision of how much to cut the body-either for the public audience or in the more private contexts of medical teaching and research-was still constrained by one key factor: time.

Corpses had an extremely limited shelf-life as useful anatomical objects before they were claimed by decay and putrification. In the period of the Murder Act, embalming and preservation techniques were rudimentary at best, and as discussed, medical men were frequently faced with difficult decisions on how long they should wait to ensure a body was dead, knowing that there was a finite amount of time for their work. Further, the timing of the Assizes (which coincided with the summer 


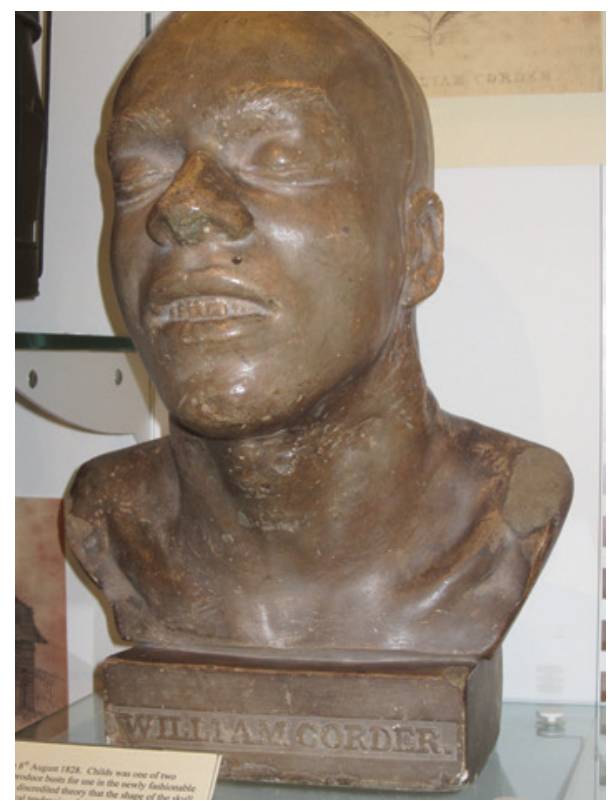

Fig. 5.2 Bust of William Corder (Photo: S. Tarlow)

sessions) meant that outside London, one of the two annual sessions at which murderers were tried, convicted, and sentenced to execution and post-mortem punishment occurred during warm months-higher temperatures accelerated decomposition, further reducing the time during which the body would be useful and safe for dissection. As Hurren has noted, it was not often possible to perform all of the anatomical procedures surgeons might wish to execute on a single body before it became overly decomposed. Instead, a 'key skill [of penal surgeons] was to dissect the maximum amount as the biological clock ticked'. ${ }^{61}$ Medical men were highly motivated, therefore, to execute their public duties under the Murder Act and satisfy the crowd as quickly and efficiently as possible, so that they could move toward the dissection and the anatomical procedures that had professional or medical value.

There were instances in which the sentence of anatomisation and dissection was not carried out or was only partially accomplished. Earl Ferrers was the only peer of the realm convicted and punished under the Murder Act, and there was considerable interest in the question of how 
much his body should be cut by the medical men. In the end, his body was anatomised and the surgeons made 'a large incision from the neck to the bottom of the thorax or breast, and another across the throat', then opening the abdomen and removing the bowels'. ${ }^{62}$ After the body was exposed to public view (both before and after the body was cut), it was dissected no further and it was taken away and buried quietly (Fig. 5.3). In the case of Thomas Gordon, hanged in August 1788 for the murder of a Constable Linnell in Northamptonshire, he had attracted considerable public sympathy by the time of his execution. As a result, 'the surgeons', the newspapers reported, 'with great humanity gave up the body to the old man and the hearse brought it to the inn where

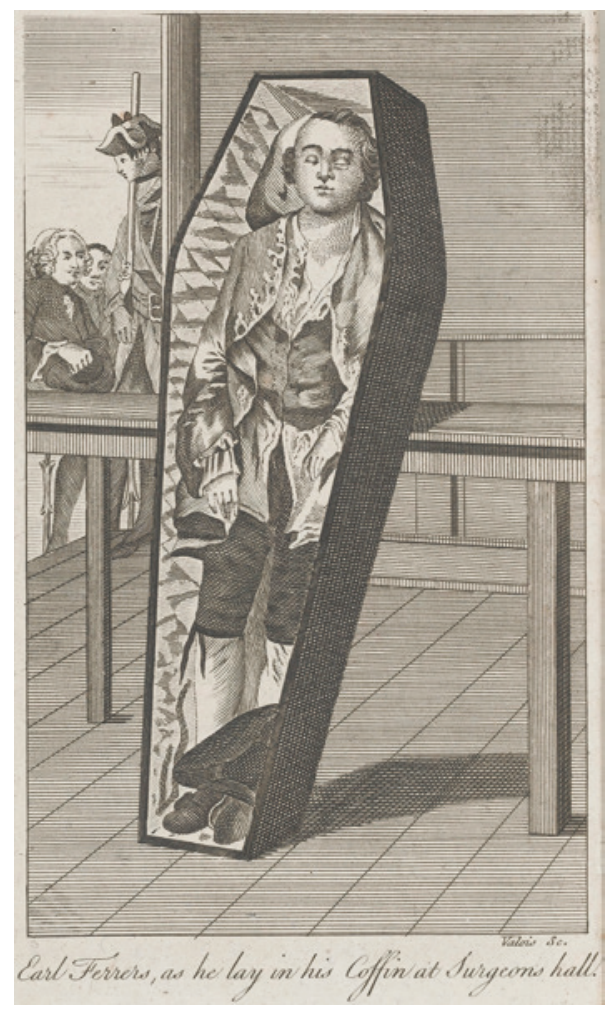

Fig. 5.3 Earl Ferrers in his coffin (Wellcome Collection) 
Mr. Gordon resides when at this town'. ${ }^{63}$ A few Murder Act corpses were spared the full extent of their post-mortem punishment because in some rural areas there was a lack of available and willing medical men to conduct the anatomisation and dissection. ${ }^{64}$ But these cases are outliers. The requirements of criminal justice, medical research and teaching, and the need to satisfy the execution crowd combined and meant that nearly all mandated post-mortem punishments were indeed carried out.

Though constrained by the terms of their official role, public expectations, social hierarchies, and the limited period during which bodies remained useful for anatomical work, medical men nonetheless exercised a degree of discretion. ${ }^{65}$ Thus, as Peter King has observed, "justice was remade from the margins of eighteenth century society', ${ }^{66}$ not in a central location in London, but in the provinces where a penal surgeon's reputation was made, remade and sometimes broken, in ways to which we now turn.

\section{AcCess And Ambition}

By condemning individuals convicted of murder to the additional post-mortem punishment of dissection, the Murder Act created an unprecedented level of legally sanctioned and secure access to human corpses for surgeons, physicians and anatomists in Britain. This is the most compelling reason why medical men cooperated with the criminal justice system, even though the association could be detrimental to their public reputation. The service they performed in the public eye offered at best slight benefits in terms of experience or research. Much more important for the penal surgeon was ensuring effective and rapid access to bodies after their duties in the name of justice were complete. Access via the Murder Act was safer and faster than through any other mechanism at the time. Alternative methods for obtaining corpses, such as grave robbing or purchasing corpses from corrupt sextons or undertakers, may have been poor second choices in terms of safety and security, but they were by far the main source of the increasingly large numbers of bodies required during a time when direct experience of working on and learning from the dissection of human corpses was gaining importance in medical training. In order for a surgeon to build a reputation that would attract fee-paying students and patients, secure access to bodies safe to use in highly public ways was required. In practice, this is what the Murder Act provided. This section considers how access to bodies and to corpses of maximum medical value worked under the Murder Act, 
and the ways that the medical men harnessed the power of the criminal corpse to enhance and establish their professional reputations during the rapid professionalisation of medicine in Britain.

The corpses of executed criminals had been granted to medical men for two centuries before the advent of the Murder Act, but not without controversy. Although the royal provision of four corpses a year to the Company of Barber Surgeons, and other similar arrangements (see Chapter 3), gave official sanction to medical men to claim selected bodies, it offered them no protection in actually taking possession of or working with corpses. Angry crowds or the families of the condemned at times challenged the medical men and their agents at the foot of the gallows as they competed for the body, and altercations could quickly become violent and unmanageable. ${ }^{67}$ This changed under the Murder Act: attempting to rescue a condemned murderer was made punishable by death; trying to remove a corpse from the possession of the medical men and their beadles was made punishable by transportation. With the advent of the Murder Act, for the first time strict and clearly mandated punishments for interfering with the bodies of those sentenced to dissection and anatomisation served to protect the medical men.

The Act also blunted the desire of many members of the public to prevent the anatomisation and dissection of corpses. By reserving postmortem harm at the hands of the surgeons as a punishment exclusively for those found guilty of murder, widely understood to be the most socially transgressive crime, the State reduced the likelihood that friends or family would try to rescue these particular bodies. Even if the horror of the crime was in doubt or did not sever familial ties of affection and loyalty, family and friends would have to contest with the disapproval of the crowd-once likely to turn on medical men, now often ardent defenders of their practice - and their potential disappointment at being denied the spectacle of anatomical post-mortem punishment. Legally and socially, the Act made the bodies of murderers sentenced to dissection and anatomisation safer and more easily accessible to the medical men than other bodies they might pursue or receive-either from the gallows or the grave.

\section{'Good Bodies': Damage, Decay and Timing}

Improved access involved not only the ability to safely secure a murderer's corpse from the site of execution, but also the speed with which the body could be made ready for anatomisation and dissection. Prior to the Murder Act, when medical men were reliant on sourcing corpses 
(except the few allocated through royal decree or other grant) through purchase, arrangement with the hangman or gaoler, or from fresh graves to meet the needs of teaching and research, securing a body shortly after death, while it was still warm or simply before decay set in, was unlikely.

The conditions under which medical men claimed bodies under the Murder Act from the gallows significantly decreased the time delay between execution and anatomisation. The Act's removal of impediments and provision of state assistance in moving and securing the body meant that the medical men could begin work on corpses much sooner after death-and indeed, were required to do so to satisfy the postexecution crowd. One of the key implications of this shift in the timing of anatomical work is that the bodies secured under the Murder Act were likely to be safer and possibly of better quality for meeting the needs of surgeons and anatomists.

Aside from the risk of being chased or attacked by an angry mob, working with corpses regardless of their criminality was dangerous. Embalming, in the form of arterial injection, was still being developed and was a rare and imprecise practice in the period of the Murder Act. No form of refrigeration (other than standard cool cellars) was available to slow the growth of both natural and invasive organisms after death. ${ }^{68}$ Sluicing the corpse with cold water, both before and after the penal surgeon started his work, was a popular way of improving the safety and longevity of corpses by washing away putrefying material and effluvia, removing some bacteria and microorganisms, and cooling the body. Similarly, shaving in preparation for anatomical work helped to make the body easier to work with and reduced the chance of transmission of some diseases by removing the habitat for lice and fleas. All the same, the risk of infection from diseased bodies carrying communicable diseases or parasitic infections was a hazard for medical men in the eighteenth and nineteenth centuries. Just a small nick from a scalpel could mean death from poisoning in the age before antibiotics and the regular use of antiseptics. William Rowley noted in 1795 that the anatomist must 'risk his own life to be serviceable to others' ${ }^{69}$ In this sense, the 'safety' of bodies vis-à-vis their anatomical use was an issue no matter their provenance. However, some risks-particularly those associated with purificationincreased as the interval between death and dissection grew. Under the Act, then, timing was a key factor in the ability of the medical men to access bodies in the most useful state possible. 
Hurren has written about the importance medical men placed on obtaining 'good bodies' during this period. ${ }^{70}$ In this sense 'good' bodies were those most useful to anatomical teaching and research. In contrast, 'bad bodies' were dirty, decayed and damaged, as well as those contaminated such as by disease or lice. Freshness of the corpse, as discussed above, was a critical feature of a 'good' body, but so was the condition of the body when it reached the medical men. A body that had been roughly handled on the gallows might be much less useful for the purpose of anatomical study. If the condemned resisted the noose, or if the hangman had to make extra efforts to ensure death on the gallows by, say, hanging a second time or pulling on the body to bring about death, the corpse was likely to be damaged. Organs that had been mashed or mangled or bones broken (all possible outcomes of execution, especially if prisoners resisted) disrupted the possibility of treating the corpse as a useful, anonymised and generalised anatomical object from which conclusions could be applied broadly to the living or compared with other dead. In this context, it is no surprise that Hurren has identified the willingness of medical men to use the lancet to ensure or cause the death of those hanged under the Murder Act as a strategy often intended to reduce rough handling of the body and thereby improve its use as an anatomical specimen..$^{71}$ No matter how much some might perceive this as illegal or immoral interference, medical men could be quite practical in protecting their own interests.

Finally, murderers convicted under the terms of the Act could be considered 'good' bodies based on their treatment while waiting to be hanged: convicted murderers were allowed only bread and water in the interval between sentencing and execution. Though the intent of this clause was to serve the interests of the criminal justice system (as discussed in the last chapter), in practice there was a clear benefit to the medical men. The contents of the stomach of a corpse could give off such a foul stench that people were occasionally knocked out if that organ was nicked during dissection, and the contents of the stomach could pollute or corrupt the surrounding body before the penal surgeons had finished their work. However, in the descriptions of dissections of bodies obtained under the Murder Act, usually very little was found in the stomach as a direct result of the punitive and restrictive pre-execution diet. This diet made the bodies safer, cleaner, and easier to work with. Further, the medical men were able to compare the anatomy of bodies that had been exposed to the same food and drink as each other-an 
important consideration when we consider contemporary understandings of how a variety of consumption practices, from binge drinking to eating highly acidic or fatty foods, can dramatically affect the body even over short periods of time. This level of standardisation of the research object (the body of the condemned) was valued by the medical men, and was only possible because of the rigidity of pre-execution treatment prescribed by the Murder Act.

\section{Corpses in the Countryside: Changing Patterns of Distribution of Anatomical Subjects}

The Murder Act changed more than the quality of bodies legally available to the medical men-it also changed the quantity of bodies nationally available for anatomical work through clearly mandated legal means and shifted the geography of scientific access to fresh cadavers.

Corpses made Available to the Surgeons under the Murder Act, 1752-1832 (including Admiralty cases)

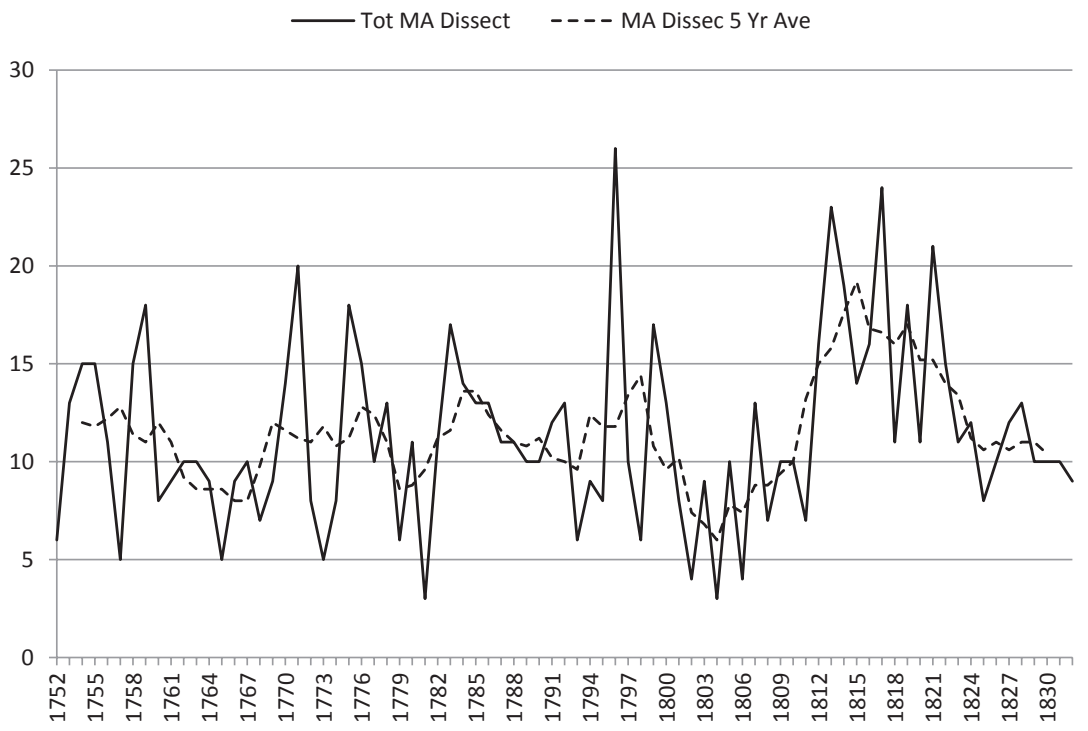

Fig. 5.4 Annual supply of bodies to medical men during the period of the Murder Act 
A total of 1150 individuals were convicted and sentenced under the Murder Act over its eighty-year 'life' (Fig. 5.4). Of these, 908 were subjected to the post-mortem punishment of dissection. The average number of corpses available annually to the medical men, 11 , certainly represents an increase over the few bodies previously permitted to the Colleges each year in the period preceding the Act under royal allowances and conventions (see Chapter 3 ). But the increase is even smaller than it might appear. There was no consistency in the number of bodies available, and while fluctuations meant that some years saw significant numbers of corpses reaching the medical men through the courts, other years saw only a very slight increase. It remained nationally true, however, that the vast majority of cadavers needed for education and research were acquired through other, extra-legal or even illegal channels.

There are broad trends in the number of legally available bodies. Most notable is the decline toward the end of the period. One of the most powerful narratives about crime and punishment in the eighteenth and nineteenth centuries is that the period evidences a transition from punishment of the body to 'gentler' forms of punishment designed to reform individuals. This period overlaps with that famously studied by Foucault, who argued that systems of criminal justice had moved away from public spectacles such as breaking on the wheel, to private discipline and punishment by removal from society, giving rise to prisons, asylums and similar penal institutions. ${ }^{72}$ However, though the number of convictions for murder under the Act decreased over our eighty-year period, this was no smooth or linear process (Fig. 5.5). The noticeable peaks suggest that greater nuance is required when tracing social change in these centuries. Further, there was a clear push from both legislators and a variety of social commentators throughout the eighteenth century to increase the number of crimes for which post-mortem punishment would be used, but these were never successful (see Chapter 4). Regardless, it is a mistake to talk about increases or decreases in the availability of corpses for dissection under the Murder Act period without attending to wider sociopolitical contexts.

These contexts also include the regionalisation of England, and the increasingly stark divisions between 'the city' (usually meaning London) and 'the countryside'. To date, London has attracted a disproportionate amount of attention in studies of British medicine and anatomy, and while this interest is somewhat justified by the availability and centralisation of judicial and medical material history, the dominance of 
Convictions under the Murder Act, 1752-1832 (including Admiralty cases)

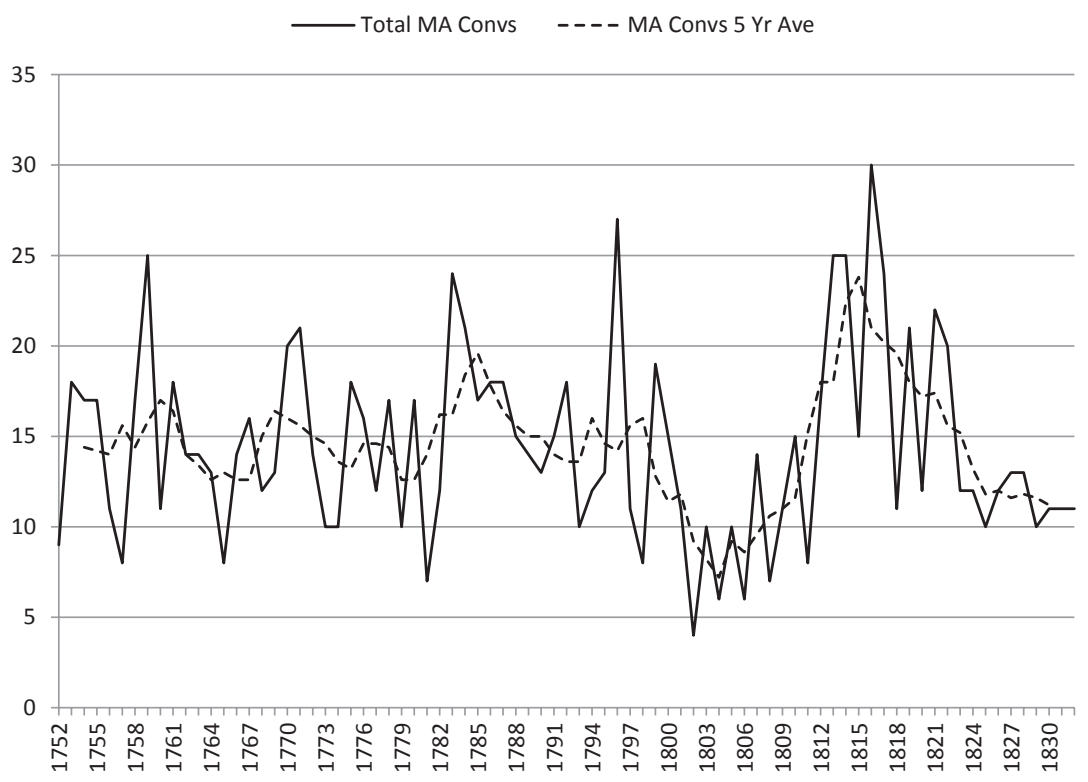

Fig. 5.5 Number of convictions per annum under the Murder Act, during the period of its operation

London over the country's medical practices changed sharply in the mid-eighteenth century. One of the key factors in London's dominance was that until 1752, London surgeons - the members of the Company of Barber-Surgeons-were the only English medical men permitted legal access to corpses for anatomical work. This created a bottleneck for anatomical teaching and research, reinforced by the monopoly of the Companies on recognised status and the lack of established hospitals elsewhere in the country that could serve as teaching and research hubs. With the advent of the Murder Act, the spatial availability of legal corpses for anatomical work shifted, spreading across England as any centre where the assizes were held (and murderers tried, convicted, sentenced and executed) became a potential source of legally sanctioned bodies for penal surgeons. This, coupled with the professionalisation of medicine and the rise of voluntary hospitals in burgeoning centres of industrial Britain over the eighteenth century, contributed to challenging London's anatomical and medical supremacy. 
Even as the spatial distribution of legally available corpses spread beyond the capital, however, it did not necessarily answer to the demands of the medical men but rather to the needs of the judiciary. Medical men may have been able to access bodies outside of London, but they still depended on state structures to produce, protect and move those bodies.

As discussed in the previous chapter, there are a number of important geographical factors to consider in understanding how and why the Murder Act was applied and enforced more in some areas than others. Just as the locations of trials, executions and public displays of anatomised criminal corpses varied considerably, so too did the geographic distribution of the bodies available to surgeons under the Murder Act.

Under the Murder Act, we have found that 148 criminal corpses were produced and anatomically consumed in London over the life of the Act-only 16.3\% of the total. Prior to the Murder Act, London (and more specifically, the Barber-Surgeons) had been allocated four criminal corpses a year for anatomical purposes. The (on average) two bodies per year available to London penal surgeons under the Act represents a $50 \%$ increase to the city's legal allocation of corpses for anatomical work. However, the shift in availability was nowhere near as significant in London as it was in regions outside the metropolis. For the counties, our project has demonstrated a far more striking change. Before 1752 there was no formal allowance of bodies to surgeons beyond London, Oxford and Cambridge; afterwards, all regions of England experienced an increase. By 1804, 'a penal surgeon had a much better chance of dissecting on a regular basis from legal sources that became available in the provinces rather than the capital'. ${ }^{73}$ In fact, the legal provision of bodies under the Murder Act helped to radically decentralise London's importance to anatomy and medicine by the first half of the nineteenth century. In the last three decades of the Act's life, anatomical research was not only possible outside London in regional centres but the conditions under which bodies were received were often more favourable, resulting in new and important research on the human body.

\section{The Value of the Criminal Corpse}

The corpses that the medical men were able to access legally under the Murder Act and through their participation in the criminal justice system, however, represented only a fraction of all the bodies actually used in anatomical research and teaching. Though better documented for the Victorian period, grave robbing to supply medical centres with bodies 
remained common and a much-needed source of anatomical material, even during the period of the Murder Act. ${ }^{74}$ Beadles employed by the Companies and anatomists themselves made arrangements to purchase or otherwise procure the bodies of convicts executed for other capital crimes from the gallows which, while not always strictly illegal, was difficult and lacked guarantees. Medical men may have to fight the friends and family of the deceased, asserting their 'natural rights' to procure the body of their deceased loved one. Alternatively, the gaoler or executioner might 'sell' the body to one surgeon prior to execution, then turn around and sell the body again to one or more other surgeons, leaving the medical men to fight amongst themselves. And while the selling of bodies in this way was often not strictly illegal, it was not precisely legal either and often raised public ire, meaning that there were few means by which medical men could seek redress for 'bad deals'.

It remains difficult to estimate the number of non-Murder Act bodies that entered the anatomical supply chain during the life of the Act, due to the covert nature of the transactions and resulting lack of formal paperwork. The Diary of a Resurrectionist, based on the diary of Joshua Naples, a body snatcher who recorded his list of activities from 18111812 , does provide a useful picture. In London in the first decades of the nineteenth century, 'the number of subjects annually available for instruction amounted to between 450 and 500' and it was estimated that about 500 students each year were working at dissection. ${ }^{75}$ Compare this to the approximately six bodies a year made available through legal means, and the scale of the use of corpses sourced through other means comes into focus. These bodies, though useful, were tainted by their illicit, unsavoury, or flatly illegal provenance. Anatomists were already grappling with negative public opinion due to their interest in bodies and the criminal or ghoulish practices required to procure them. To make public use of such bodies in demonstrations, lectures, or research, risked reinforcing pejorative associations to the detriment of the surgeon's reputation (and that of the profession). Worse, courting the risk of being exposed to public censure, to use bodies of questionable provenance publicly might prompt inquiries from the police, and criminal charges. For all these reasons, the criminal corpses available to medical men under the Murder Act were particularly valuable.

In the eighteenth and nineteenth centuries, medicine was not necessarily a well-paid profession. For this reason, ambition was crucial-a surgeon needed to develop a wide and dynamic reputation 
in order to capitalise on their skills. A surgeon had to do a good deal of self-promotion to establish the kind of reputation that would ensure a robust client list, particularly one made up of individuals and families that paid regularly. In addition, it was desirable for medical men to diversify their income streams to insulate against the vagaries of medical practice and extend their professional reputation. Teaching, public lectures or demonstrations, and original research were key activities for an ambitious-and solvent!-surgeon. And these activities required anatomical material: that is, bodies that could be used in highly visible ways that were legally 'safe'. Criminal corpses obtained under the Murder Act fit the bill. As Hurren has noted of Sir William Blizard, he was 'an ambitious man determined to establish his reputation in medical circles by undertaking gallows work so that he could stand centre-stage in the best dissection theatres of London'. ${ }^{76}$ Indeed, 'To establish a good business reputation for medical innovation it was important to be seen to receive bodies from the hangman in a local area on a concerted basis'. ${ }^{77}$ Surgeons worked over years to secure preferential access to the legally sanctioned bodies available under the Murder Act. Though taking on a role within the criminal justice system by anatomising and dissecting the bodies of convicted, executed murderers risked strengthening the connection in the public eye between criminality and anatomy, it was worth it if the result was the opportunity to build a reputation and profitable career based on completely aboveboard anatomical practice on legally sanctioned bodies.

In addition to being employed for the practice and demonstration of anatomical procedures, ambitious surgeons made use of criminal cadavers to bolster their professional reputation by engaging in original research. The results of experimentation on the bodies made available under the Murder Act carried little risk in terms of public disgust or disapproval as their crime had already given rise to social exclusion, and could therefore be disseminated and demonstrated because the bodies were legally obtained. Elizabeth Hurren has identified the types of research conducted on Murder Act corpses by 1800, and it varied widely as a result of the variability in availability of these criminal corpses. ${ }^{78}$ For example, research on the brain and medical death took place in Leicester, on the brain and nervous system in Derby, and on gonorrhoea, heart resuscitation and breast tissue in Ipswich. A particularly intriguing area of research undertaken in the first decades of the nineteenth century involved the application of electricity to a recently dead body. Galvanism took its name from the Italian scientist Luigi 
Aloisio Galvani (1737-1798) who discovered 'animal electricity' when he found that the muscles of dead frogs twitched on the application of an electrical spark. ${ }^{79}$ Proponents of galvanism saw the best possibilities in experimentation on the bodies of the recently dead, but not those who had died of a disease. Again, Murder Act corpses fit the bill. The application of electricity to a recently dead body provoked muscle contractions that could make a corpse twitch and jerk, and in one particularly arresting demonstration on the corpse of Matthew Clydesdale (d. 1818), after connecting rods to the diaphragm and the left phrenic nerve, his chest rose and fell as if still breathing-a scene that horrified witnesses. ${ }^{80}$ That the evidently dead corpse exhibited movement mimicking life was a source of fascination and horror (Fig. 5.6). The possibility that galvanism could lead to the reanimation of a corpse was a subject of discussion and astonishment, and is mentioned by Mary Shelley as an influence on Frankenstein. ${ }^{81}$

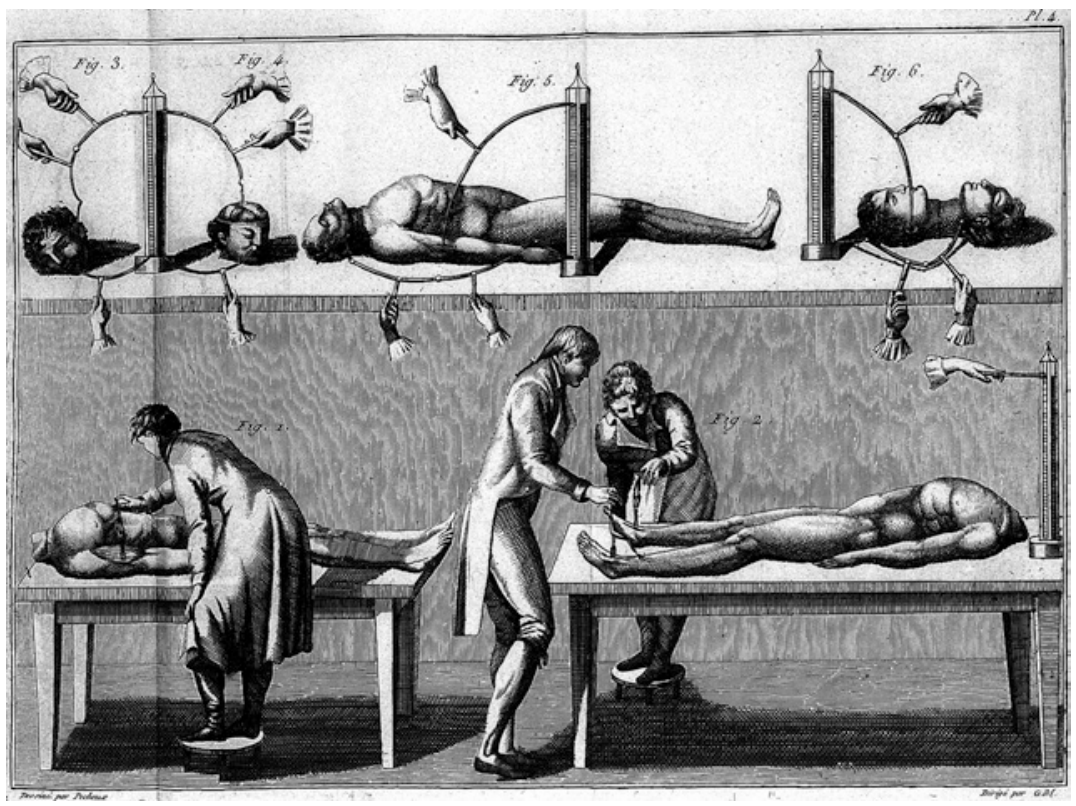

Fig. 5.6 Giovanni Aldini conducting experiments in galvanism (Wellcome Collection) 


\section{The End of Dissection and Anatomisation in the Criminal Justice System}

In 1832 the anatomisation and dissection of convicted murders was removed as a judicial punishment in Britain. The reasons for this were many, including changing public opinion and the long decline in executions in Britain more generally, but the needs of the medical men played a significant role. First, the Burking scandal of 1828 in Edinburgh in which a series of 16 murders were undertaken by William Burke and William Hare in order to sell the corpses to anatomists, underscored the urgent need to reform the system of body supply for medical training and experimentation. There simply were not enough bodies made legally available to medical professionals, and while the Murder Act had made some bodies of better quality accessible to penal surgeons, the shortfall was severe and access still limited within the wider medical profession. Reflecting changing public opinion and in an effort to make more bodies available to medical men, the Anatomy Act was passed in 1832. It removed anatomisation and dissection as judicial punishments, and made the bodies of paupers unable to cover the costs of burial available to be claimed for medical training and research. However-like some bull-necked prisoners-the connection between dissection and criminality died hard, and persisted in the minds of many for some time. Just as convicted murderers balked at the prospect of dissection and anatomisation as a post-mortem punishment, so too did the poor and vulnerable display clear horror at the prospect of their bodies being cut, interfered with, or kept from decent burial. ${ }^{82}$

Today, dissection remains a core aspect of medical training. It is increasingly common for people to donate their bodies voluntarily for scientific and medical research. That dissection remains an important part of medical training, and social attitudes towards the practice have shifted in broad terms, underscores how the continued advances in medical knowledge today are built on the foundations established in the eighteenth century. The medical men who conducted dissections under the Murder Act were clearly trying to balance multiple needs and expectations - of the courts, of the crowds, of fellow medical practitioners and while it is difficult to track specific anatomical 'discoveries' through the penal dissection of executed murderers in England, it is safe to say that these dissections at the least ensured that understanding of human anatomy spread and grew, among both medical professionals and the general public. 
More than this, however, the involvement of medical men in the dissection of criminal corpses showed the need to professionalise and standardise the conditions under which bodies were secured and new medical professionals trained. By bringing the work of surgeons into the public eye, the scandals of body snatching (and Burking) were balanced against a narrative of dissections as increasingly 'normal' and beneficial, as the celebrated philosopher and social reformer Jeremy Bentham advocated. ${ }^{83}$ Further, just as the specific references to 'surgeons', 'anatomisation' and 'dissection' in the Murder Act led to a significant change in how medical men approached working with bodies, so too did the Anatomy Act seek to separate 'dissection' from criminality.

But not all criminal corpses could be co-opted into a narrative of progressive human betterment. A substantial minority of those convicted under the Murder Act were destined to participate in an entirely different spectacle of the macabre: hanging in chains.

\section{Notes}

1. See for example, Gatrell, V.A.C. (1996), The Hanging Tree: Execution and the English People 1770-1868 (Oxford: Oxford University Press).

2. See, Bennett, R.E. (2018), Capital Punishment and the Criminal Corpse in Scotland 1740-1834 (Palgrave Macmillan); Hurren, E.T. (2016), Dissecting the Criminal Corpse: Staging Post-execution Punishment in Early Modern England (London: Palgrave Macmillan).

3. See for example, McCorristine, S. ed. (2017), When Is Death?: Interdisciplinary Perspectives on Death and Its Timings (Palgrave Macmillan); Tarlow, S. (2017), The Golden and Ghoulish Age of the Gibbet in Britain (London: Palgrave Macmillan); Hurren, E. (2016), Dissecting the Criminal Corpse: Staging Post-execution Punishment in Early Modern England (London: Palgrave Macmillan); Davies, O. and Matteoni, F. (2016), Executing Magic: The Power of Criminal Bodies (Basingstoke: Palgrave).

4. 25 Geo II c.37. An Act for Better Preventing the Horrid Crime of Murder (British law).

5. See, Hurren, E. (2016), Dissecting the Criminal Corpse: Staging Postexecution Punishment in Early Modern England (London: Palgrave Macmillan).

6. In addition to Gatrell's seminal. The Hanging Tree, the work of Simon Devereaux is particularly useful on this subject. 
7. See, Hurren, E.T. (2016), Dissecting the Criminal Corpse: Staging Postexecution Punishment in Early Modern England (London: Palgrave Macmillan), quote at p. 5.

8. 25 Geo II c.37. An Act for Better Preventing the Horrid Crime of Murder (British law).

9. Hurren, E.T. (2016), Dissecting the Criminal Corpse: Staging Postexecution Punishment in Early Modern England (London: Palgrave Macmillan).

10. As Sean McConville has observed, 'Regular prison employment of surgeons did not begin until after 1774, when the Gaol Distemper Act permitted magistrates to appoint 'an experienced Surgeon or Apothecary' to attend the prison'. See, McConville, S. (1981), A History of English Prison Administration (London: Routledge), quote at p. 76.

11. See, Hurren, E.T. (2016), Dissecting the Criminal Corpse: Staging Postexecution Punishment in Early Modern England (London: Palgrave Macmillan), p. 3.

12. See, Richardson, R. (2000), Death, Dissection and the Destitute (Chicago: Chicago University Press).

13. 25 Geo II c.37. An Act for Better Preventing the Horrid Crime of Murder (British law).

14. Always conscious, of course, of the role of the crowd in influencing these decisions, discussed briefly in the previous chapter and expanded further in this chapter.

15. See, Hurren, E.T. (2016), Dissecting the Criminal Corpse: Staging Postexecution Punishment in Early Modern England (London: Palgrave Macmillan), p. 71.

16. See discussion of the medical and osteological process of hanging in, Waldron, T. (1996), 'Legalised Trauma', International Journal of Osteoarchaeology, Vol. 6, Issue 1, 114-118.

17. The 'long drop' was introduced in the 1880s, though, as noted by Vic Gatrell, it did not always guarantee a quick death. See, Gatrell, V.A.C. (1996), The Hanging Tree: Execution and the English People 1770-1868 (Oxford: Oxford University Press), pp. 53-54.

18. For a comparative view of European execution methods, see Davies, O. and Matteoni, F. (2016), Executing Magic: The Power of Criminal Bodies (Basingstoke: Palgrave).

19. For a discussion of the effects of short drop hanging on the body, see Gatrell, V.A.C. (1996), The Hanging Tree: Execution and the English People 1770-1868 (Oxford: Oxford University Press), pp. 45-46; Hurren, E.T. (2016), Dissecting the Criminal Corpse: Staging Post-execution Punishment in Early Modern England (London, Palgrave Macmillan), p. 75. 
20. See, Hurren, E.T. (2016), Dissecting the Criminal Corpse: Staging Postexecution Punishment in Early Modern England (London: Palgrave Macmillan), p. 75.

21. Ibid.

22. Ibid.

23. Ibid., p. 34.

24. For accounts of executioners hanging on the legs of the body to ensure death, see Gatrell, V.A.C. (1996), The Hanging Tree: Execution and the English People 1770-1868 (Oxford: Oxford University Press), p. 48.

25. Elizabeth Hurren describes the infamous case of 'half-hanged MacDonald', in Dissecting the Criminal Corpse (Chapter 1, she quotes the Newcastle Courant, 14 October 1754). Ewan MacDonald was convicted of murder in September 1754 in Newcastle, and sentenced to anatomisation and dissection. After his body was cut down from the gallows and laid out on the dissection table, he revived and sat up. A young surgeon promptly dispatched him with a mallet.

26. This data is available online at http://www.capitalpunishmentuk.org/ half_hanged.html (Accessed 19 July 2017).

27. The number and geographical distribution of reprints attest to the popularity of Winslow's work. See for example, Winslow, J.B. (1746), The Uncertainty of the Signs of Death, and the Dangers of Precipitate Internments and Dissections, Demonstrated (London: Printed by M. Cooper), reprinted in 1748 in Dublin by George Faulkner; Winslow, J.B. (1749), Dissertation sur L'incertitude des signes de la Mort et L'abus des enterremens \& embaumemens précipités, trans. J.J. Bruhier (Paris: De Bure l'Ainé), reprinted in 1752; more recently in 2010 by Gale ECCO, Print Editions.

28. Winslow, J.B. (1746), The Uncertainty of the Signs of Death, and the Dangers of Precipitate Internments and Dissections, Demonstrated (London: Printed by M. Cooper), p. 9.

29. Ibid., quoted at p. 23.

30. Ibid., p. 24, quoting, Terilli, D. (1615), De causis mortis repentinae tractatio in qua etiam disputatur quid sit mors et vita in genere et quae mortis causae communes, singula vero quae de causis mortis repentinae enarrantur (Venice).

31. Ibid., p. 23, quoting Riolanus or John Riolan (the Younger).

32. The murder is described in The Newgate Calendar, popular in the eighteenth and nineteenth centuries as a collection of stories associated with executions. An online version is available at http://www.exclassics. com/newgate/ngintro.htm (Accessed 21 April 2017).

33. See, Hurren, E.T. (2016), Dissecting the Criminal Corpse: Staging Postexecution Punishment in Early Modern England (London: Palgrave Macmillan), p. 91. 
34. Ibid., quote on p. 52.

35. Ibid., p. 59.

36. Ibid., p. 96.

37. Ibid., p. 43.

38. On the crowd, see Gatrell, V.A.C. (1996), The Hanging Tree: Execution and the English People 1770-1868 (Oxford: Oxford University Press); Laqueur, T. (1989), 'Crowds, Carnival and the State in English Executions, 1604-1868', in Beier, A.L., Cannadine, D., and Rosenheim, J.M. (eds.), The First Modern Society: Essays in English History in Honour of Lawrence Stone (Cambridge: Cambridge University Press), pp. 305-355.

39. Laqueur, T. (1989), 'Crowds, Carnival and the State in English Executions, 1604-1868', in Beier, A.L., Cannadine, D., and Rosenheim, J.M. (eds.), The First Modern Society: Essays in English History in Honour of Lawrence Stone (Cambridge: Cambridge University Press), pp. 305355, quote at p. 309.

40. See, Linebaugh, P. (1975), 'The Tyburn Riot Against the Surgeons', in Hay, D., Linebaugh, P., and Thompson, E. (eds.), Albion's Fatal Tree: Crime and Society in Eighteenth-Century England (New York: Pantheon Books), pp. 65-119.

41. This extends to the other post-mortem punishment mandated in the Act, hanging in chains, as will be seen in the next chapter.

42. For example, Mary Hindes, who was sentenced to execution and hanging in 1768 for the murder of a child was 'moved considerably' by the dissection part of her sentence, according to the London Gazetteer, I July 1768. In 1785, William Higson was described in the General Evening Post of Saturday, 9 April 1785 as being more shocked at the dissection part of his sentence than at the death itself.

43. See for example the multiple interpretations of the reason for William Jobling's execution and gibbeting, in the next chapter.

44. See, Hurren, E.T. (2016), Dissecting the Criminal Corpse: Staging Postexecution Punishment in Early Modern England (London: Palgrave Macmillan), p. 199.

45. Ibid., p. 174 .

46. Ibid., p. 182.

47. Ibid., p. 184.

48. Ibid.

49. Ibid., quote at p. 210 .

50. Ibid., p. 209.

51. Ibid.

52. See, Hurren, E.T. (2016), Dissecting the Criminal Corpse: Staging Postexecution Punishment in Early Modern England (London: Palgrave Macmillan). 
53. Hurren noted that in Surgeon's Hall (London), in the mid-eighteenth century, repair bills indicate that glass had to be replaced from time to time because the crowd sometimes stoned the building to protest 'a controversial criminal dissection'. See, Hurren, E.T. (2016), Dissecting the Criminal Corpse: Staging Post-execution Punishment in Early Modern England (London: Palgrave Macmillan), quote at p. 35.

54. See, Hurren, E.T. (2016), Dissecting the Criminal Corpse: Staging Postexecution Punishment in Early Modern England (London: Palgrave Macmillan).

55. Ibid., p. 41.

56. For a comprehensive account of this infamous case and further detail about his punishment, see McCorristine, S. (2014), William Corder and the Red Barn Murder (Basingstoke: Palgrave Macmillan).

57. The Standard, Wednesday 13 August 1828, Issue 387.

58. Shaving served several purposes: it removed the habitat for certain parasites therefore making the body safer for the medical men to handle-see, Hurren, E.T. (2016), Dissecting the Criminal Corpse: Staging Post-execution Punishment in Early Modern England (London: Palgrave Macmillan), p. 92-and it exposed the skull which made the popular dissection procedure of craniotomy easier and more visually effective, allowed phrenologists to make their examinations, and also permitted the taking of plaster casts for future research or display.

59. The seven anatomical methods of a 'complete dissection' are listed in, Hurren, E.T. (2016), Dissecting the Criminal Corpse: Staging Postexecution Punishment in Early Modern England (London: Palgrave Macmillan), p. 161. They are listed as follows: Osteology (study of bones); Sarcology (study of the soft or fleshy parts of the body); Myology (study of the muscular system); Splanchnology (study of viscera and its vital organs situated in the thoracic, abdominal and pelvic cavities of the body, primarily heart and lungs, but also intestines and kidneys); Angeiology (study of the circulatory system and the lymphatic system, including arteries, veins and lymphatic vases); Neurology (study of the brain and nervous system); Adenology (study of the glands and hormonal system).

60. The Standard, Wednesday 13 August 1828, Issue 387.

61. See, Hurren, E.T. (2016), Dissecting the Criminal Corpse: Staging Postexecution Punishment in Early Modern England (London: Palgrave Macmillan), quote at p. 161.

62. See, Memoirs of the life of Laurence Earl Ferrers, Viscount Tamworth. Together with a more particular and circumstantial account of his Lordship's behaviour during the whole time of his confinement, and at the place of his execution, than has hitherto been published (1760) (London: Printed for J. Coote, at the King's-Arms, in Pater-noster-Row), p. 56. 
63. For newspaper reports see, Oracle Bell's New World, 21 August 1789; London Chronicle, 20 August 1789; London Gazette, 7 April 1752; London Evening Post, 21 March 1752. For an excellent and extensive investigation into this case, see Gray, D. and King, P. (2013), 'The Killing of Constable Linnell: The Impact of Xenophobia and of Elite Connections in Eighteenth-Century Justice', Family \& Community History, Vol. 16, Issue 1, 3-31.

64. For more detail see, Hurren, E.T. (2016), Dissecting the Criminal Corpse: Staging Post-execution Punishment in Early Modern England (London: Palgrave Macmillan).

65. Ibid.

66. See, King, P. (2006), Crime and Law in England, 1750-1840: Remaking Justice from the Margins (Cambridge: Cambridge University Press).

67. See, Linebaugh, P. (1975), 'The Tyburn Riot Against the Surgeons', in Hay, D., Linebaugh, P., and Thompson, E. (eds.), Albion's Fatal Tree: Crime and Society in Eighteenth-Century England (New York: Pantheon Books), pp. 65-119.

68. During the eighteenth century, technical developments in the science of embalming the dead allowed for the preservation of teaching and research specimens, but such processes were limited in scope and occurrence through most of the period considered in this book. See, Mayer, R. (2000), Embalming: History, Theory and Practice (New York: McGraw Hill).

69. See, Rowley, W. (1795), On the Absolute Necessity of Encouraging, Instead of Preventing or Embarrassing the Study of Anatomy... Addressed to the Legislature of Great Britain (London: ECCO), p. 6.

70. See, Hurren, E.T. (2016), Dissecting the Criminal Corpse: Staging Postexecution Punishment in Early Modern England (London: Palgrave Macmillan), pp. 70-71.

71. Ibid., p. 36 , pp. $56-59$.

72. Foucault, M. (1977), Discipline and Punish: The Birth of the Prison (New York: Pantheon Books).

73. Ibid., quote at p. 178.

74. See, Hurren, E.T. (2012), Dying for Victorian Medicine: English Anatomy and Its Trade in the Dead Poor, c.1834-1929 (Basingstoke: Palgrave Macmillan).

75. See, Bailey, J.B. (1896), The Diary of a Resurrectionist (London: S. Sonnenschien \& Co.), quote at p. 70.

76. See, Hurren, E.T. (2016), Dissecting the Criminal Corpse: Staging Postexecution Punishment in Early Modern England (London: Palgrave Macmillan), quote at p. 155.

77. Ibid., quote at p. 126. 
78. Ibid., p. 248.

79. See, Lawrance, R.M. (1853), On the Application and Effect of Electricity and Galvanism in the Treatment of Cancerous, Nervous, Rheumatic, and Other Affections (London: H. Renshaw).

80. See, Bennett, R.E. (2018), Capital Punishment and the Criminal Corpse in Scotland 1740-1834 (Palgrave Macmillan).

81. Mary Shelley, Preface to the 1831 edition, Frankenstein.

82. On the impact of the Anatomy Act, see the excellent work of Richardson, Ruth (2000), Death, Dissection and the Destitute (Chicago: Chicago University Press).

83. Bentham gave his own body for dissection when he died in 1832 to help reduce the stigma of dissection and to encourage others to voluntarily donate their bodies for scientific research.

Open Access This chapter is licensed under the terms of the Creative Commons Attribution 4.0 International License (http://creativecommons.org/licenses/ by $/ 4.0 /$ ), which permits use, sharing, adaptation, distribution and reproduction in any medium or format, as long as you give appropriate credit to the original author(s) and the source, provide a link to the Creative Commons license and indicate if changes were made.

The images or other third party material in this chapter are included in the chapter's Creative Commons license, unless indicated otherwise in a credit line to the material. If material is not included in the chapter's Creative Commons license and your intended use is not permitted by statutory regulation or exceeds the permitted use, you will need to obtain permission directly from the copyright holder.

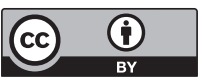

